1 This is the peer reviewed version of the following article: Diabetes, Obesity and

2 Metabolism. A Journal of Pharmacology and Therapeutics, volume 21, issue 11, pages

3

2526-2534 (2019), which has been published in final form at https://doi.org/10.1111/dom.1383. This article may be used for non-commercial purposes in accordance with Wiley Terms and Conditions for Self-Archiving.

\title{
PREVENTION OF TYPE 2 DIABETES IN PREDIABETIC PATIENTS BY USING \\ FUNCTIONAL OLIVE OIL ENRICHED IN OLEANOLIC ACID: THE PREDIABOLE STUDY, A RANDOMISED CONTROLLED TRIAL
} Running title: Prevention of diabetes with oleanolic acid
José M. Santos-Lozano ${ }^{\mathrm{a}, \mathrm{b}, \mathrm{c}}$ Mirela Rada $^{\mathrm{d}}$, José Lapetra ${ }^{\mathrm{a}, \mathrm{e}}$, Ángeles Guinda ${ }^{\mathrm{d}}$, María C. Jiménez-Rodríguez ${ }^{a}$, José A. Cayuela ${ }^{b}$, Antonio Ángel-Lugo ${ }^{a}$, Ángel Vilches-Arenas ${ }^{\dagger}$, Ana M. Gómez-Martín $^{\mathrm{b}}$, Manuel Ortega-Calvo ${ }^{\mathrm{a}}$, José M. Castellano ${ }^{\mathrm{d}^{*}}$.

${ }^{a}$ CIBER Fisiopatología de la Obesidad y Nutrición (CIBEROBN), Instituto de Salud Carlos III, Madrid, Spain

${ }^{b}$ Department of Family Medicine, Primary Health District Seville, Seville, Spain 'Department of Medicine, Faculty of Medicine, University of Seville, Spain

${ }^{\mathrm{d}}$ Food and Health Department, Instituto de la Grasa, Spanish National Research Council (CSIC), Seville, Spain

${ }^{e}$ Andalusian Public Foundation for the Management of Health Research in Seville (FISEVI), Seville, Spain.

'Department of Preventive Medicine and Public Health, Faculty of Medicine, University of Seville, Spain

\footnotetext{
${ }^{*}$ Corresponding author: José M. Castellano. Institute de la Grasa-CSIC. Campus University Pablo de Olavide, Building 46. 41013-Seville (SPAIN). phone number+34654611550. e-mail: jmcas@ig.csic.es
} 
6

Abstract word count: 206

Main body of text word count: 3685

Number of references: 40

Number of Tables: 3

Number of Figures: 2 


\section{ABSTRACT}

2 Aims/hypothesis Oleanolic acid (OA), a natural component of olive (Olea europaea L.), has 3 demonstrated antidiabetic action in vitro and in experimental animals. However, a similar 4 action has not been proved in humans. The PREDIABOLE (PREvention of DIABetes with 5 OLEanolic acid) Study is a randomised and controlled trial, performed in primary care, 6 designed to assess whether the regular intake of an OA-enriched olive oil is effective in the 7 prevention of diabetes.

8 Methods Prediabetic individuals (IFG + IGT) of both sex (176 patients, 30-80 years old) were 9 randomised to receive $55 \mathrm{~mL} /$ day of $\mathrm{OA}$-enriched olive oil (equivalent-dose $30 \mathrm{mg} \mathrm{OA} /$ day) 10 (intervention group; IG) or the same oil not enriched (control group; CG). Main outcome was 11 the incidence of new onset type 2 diabetes in both groups.

12 Results Forty-eight new diabetes cases occurred, 31 in the CG and 17 in the IG. Multivariate13 adjusted hazard ratio was $0.45(95 \% \mathrm{Cl}, 0.24-0.83)$ for the IG when compared with the CG. 14 Intervention-related adverse effects were not reported.

15 Conclusion/perspectives The intake of OA-enriched olive oil reduces the risk of developing 16 diabetes in prediabetic patients. The results of the PREDIABOLE trial promotes the use of OA 17 in new functional foods and drugs for the prevention of diabetes in individuals at risk of developing it. 


\section{INTRODUCTION}

Diabetes, one of the most prevalent chronic diseases, represents a major public health problem worldwide. According to the International Federation of Diabetes, there were 425 million diabetic people in 2017 , and a significant increase in the prevalence is expected in the next years, estimating that the number of diabetics in the world will achieve 629 million in 2045.

An essential topic of diabetes approach is prevention, especially in people at high risk.

Diabetes is preceded by a period of dysglycemia, known as prediabetes, ${ }^{2}$ in which plasma glucose is higher than normal but not meet the criteria for diabetes. Prediabetes is defined by impaired fasting glucose (IFG), and/or impaired glucose tolerance (IGT) and/or a glycated hemoglobin $(\mathrm{HbA1C})$ in the range $5.7-6.4 \%(39-47 \mathrm{mmol} / \mathrm{mol}) .^{3}$ Prediabetes is associated with obesity, dyslipidemia with hypertriglyceridemia and/or low HDL-cholesterol, and hypertension. Compared to euglycemics, people with both IFG and IGT have 20-fold higher risk of developing type 2 diabetes. ${ }^{4,5}$ Therefore, they are ideal target population to investigate new preventive strategies against diabetes at short time.

Oleanolic acid (OA; 3b-hydroxy-olean-12-en-28-oic acid) is a plant secondary metabolite, widely distributed as free acid or aglycone of triterpenoid saponins. ${ }^{6}$ It is especially abundant in the olive tree (Olea europaea L.), as component of the cuticle waxes that cover fruit and leaf epidermis. ${ }^{7} \mathrm{OA}$ is also natural component of olive oils. ${ }^{8}$ This triterpene has a wide range of biological activities, ${ }^{9-12}$ including an antidiabetic action. ${ }^{13,14}$ OA improves insulin action, preserves functionality and survival of $\beta$-cells, and protects against micro- and macrovascular complications of diabetes, throughout a complex and multifactorial mechanism. ${ }^{14}$

Pharmacological potential of OA has been demonstrated in experimental models, but studies in humans are very scarce. ${ }^{12,15-17}$ A likely reason could be the belief of its poor bioavailability. ${ }^{18-}$ ${ }^{20} \mathrm{~A}$ recent pharmacokinetic study in humans, ${ }^{21}$ administering OA dissolved in olive-pomace oil, has proved good bioavailability for the triterpene, 35-50 folds higher than when administered as micronized powder. ${ }^{22,23}$ 
1 Lifestyle changes have revealed effective in preventing or delaying diabetes, and the inclusion

2 in the diet of functional foods containing bioavailable OA could be an interesting strategy. With

3 this aim, we have performed the PREDIABOLE Study, a randomised trial designed to assess

4 whether the regular intake of an OA-enriched olive oil may be effective in preventing the 5 progression to diabetes in prediabetic individuals with IFG and ITG.

6

7 SUBJECTS AND METHODS

8 Design Overview

9 The PREDIABOLE (PREvention of DIABetes with OLEanolic acid) Study is a parallel-group, randomised, controlled, double-blind, and multicentre trial, entirely performed in primary care from June 2010 to November 2016. Participants in the trial were assigned in a 1:1 ratio to one of the two study groups: diet with OA-enriched olive oil (intervention group, IG), or the same diet with not enriched olive oil (control group, CG).

\section{Settings and Participants}

Eligible participants were community-dwelling men and women (aged 30 to 80 years), diagnosed of IFG + IGT, according to ADA's criteria at $2008,{ }^{24}$ with overweight/obesity (bodymass index $25.0-39.9 \mathrm{~kg} / \mathrm{m}^{2}$ ), that provided written informed consent to participate in the study. Pregnant women and those within 3 months postpartum or breastfeeding were not included. Exclusion criteria were a history of IFG and/or IGT longer than seven years, diabetes or the use of hypoglycemic agents. People with alcohol dependence, drug addiction, and physical or intellectual limitations were also excluded. Other exclusion criteria were fasting triglycerides $>600 \mathrm{mg} / \mathrm{dL}$ despite treatment, Grade 3 Hypertension (SBP $\geq 180 \mathrm{~mm} \mathrm{Hg}$ and/or DBP $\geq 110$ $\mathrm{mm} \mathrm{Hg}$ ) according to 2007 guidelines by the European Society of Hypertension, suboptimaltreated thyroid disease or others endocrine diseases and cancer treatment. Finally, people using systemic glucocorticoids, selective reuptake inhibitors of serotonin or other drugs for weight reduction were also excluded. 
2 Recruitment and randomised allocation

3 Twenty-five primary care centres of Seville (Spain) participated in the study. Through an 4 opportunistic recruitment, individuals diagnosed of IFG [with at least two fasting glucose 5 values in the range $100-125 \mathrm{mg} / \mathrm{dL}(5.6-6.9 \mathrm{mmol} / \mathrm{L})$ in the last six months] were identified by

6 their family physicians, and derived to the study coordination centre, where they underwent a 7 standard $75 \mathrm{~g} \mathrm{OGTT.}{ }^{25}$ Those individuals with IGT [2-h postload glucose $140-199 \mathrm{mg} / \mathrm{dL}$ (7.8$811.1 \mathrm{mmol} / \mathrm{L})]$, and meeting the other inclusion criteria and none of the exclusion ones were 9 randomly assigned to the study groups. Allocation was performed following computergenerated random numbers prepared by the trial coordinator. Four strata of randomization were built by sex and age (cut-off 60 years). The study nurse requested by phone the assignment of participants to the two study groups at the time of admission (centralized randomization)

\section{Elaboration and characteristics of the functional olive oil}

A commercial blend of virgin and refined olive oils (control oil) was selected by its low content of minor components (phenolics, phytosterols, tocopherols, etc.) in order to minimize the influence of their bioactivity. The functional olive oil enriched at $600 \mathrm{mg} \mathrm{OA} / \mathrm{kg}$ was elaborated from the control oil by adding OA ( $\geq 97 \%$ purity) obtained from olive leaves. ${ }^{26,27}$ No other substance was added as adjuvant. Every six months, 500L-batches of control and functional oils were elaborated and bottled in $250 \mathrm{~mL}$ green-coloured flasks and labelled with a six alphanumeric characters' code for blinding. Participants, physicians and nurses were unaware of it.

Five bottles of both oil types were aleatory selected from each semiannually elaborated batches, and analysed for the chemical composition as well as the physico-chemical quality indexes, following official methods. ${ }^{28,29}$ Representative chemical composition of the oils are shown in Supplementary Appendix. In addition, the Official Panel of the Instituto de la Grasa- 
1 CSIC carried out the sensory evaluation, ${ }^{30}$ and did not find significant differences between

2 both oil types in odour, taste and appearance.

\section{$4 \quad$ Intervention and follow-up}

5 Participants were instructed to intake $55 \mathrm{~mL} /$ day of the assigned oil, preferably raw and freely 6 distributed among the three main meals. They were followed up for up to 30 months from 7 recruitment, according to a programmed schedule of visits. At baseline and quarterly 8 thereafter, all participants received six litres of the assigned olive oil for free, and were 9 submitted to anthropometric and blood pressure measurements. They were also interviewed about gastrointestinal disarrays or other kind of discomfort, and filled in a questionnaire about lifestyle (diet, physical activity, alcohol and tobacco consumption), medical conditions, and use of medication. Participants participated also in Workshops about healthy foods, recipes, seasonal shopping lists, and the culinary use of olive oil. They were likewise advised for the avoiding of fast/highly processed food, pastries, as well as sweetened and alcoholic drinks. At baseline and every six months afterwards, fasting blood samples were withdrawn from the cubital vein, and collected in sterile plastic tubes with vacuum system. The tubes were subsequently centrifuged at origin, to separate plasma from the blood cells. The plasma samples were transported at $4-7^{\circ} \mathrm{C}$ in insulated containers, within a gap of 4 hours, to the Laboratory of Analysis and Clinical Biochemistry of the Virgen del Rocio University Hospital of Seville, where they were analyzed for glucose, insulin, glycated hemoglobin (HbA1c), and hs$\mathrm{RCP}$, as well as for triglycerides, total cholesterol, HDL, and LDL. At each annual visit, an OGTT was done after a 12-hour fast, following the WHO recommendations. To see a detailed report on the laboratory techniques used, please address to the Supplementary Apendix 3, which shows a full version of the PREDIABOLE protocol.

\section{Compliance to allocation}


1 Adherence to the dietary intervention was assessed through the self-reported compliance

2 Haynes-Sackett test ${ }^{31}$ and the return of empty bottles presumably consumed. Moreover, plasma OA was analysed in a randomised collection of blood samples from 25 individuals per study group, corresponding to $0,12,18$ and 30 months of follow-up, according to Rada et al. ${ }^{21}$

\section{Outcomes}

The primary outcome was new-onset diabetes, diagnosed according to ADA's criteria ${ }^{24}$ at 2008: fasting plasma glucose $\geq 126 \mathrm{mg} / \mathrm{dL}$ ( $7.0 \mathrm{mmol} / \mathrm{L})$ or symptoms of hyperglycemia and a casual plasma glucose $>200 \mathrm{mg} / \mathrm{dL}(11.1 \mathrm{mmol} / \mathrm{L})$ or $2 \mathrm{~h}$ plasma glucose $\geq 200 \mathrm{mg} / \mathrm{dL}(11.1$ $\mathrm{mmol} / \mathrm{L}$ ) during a standard 75-g OGTT. In the absence of unequivocal hyperglycemia, these criteria were confirmed by repeat testing on a different day. The case ascertain was definitively done by the PREDIABOLE Clinical Event Committee, whose members were blinded to allocation in the study groups. New-diabetic individuals were informed and referred to their family doctors, and subsequently left out the study. As secondary outcomes we obtained data about blood parameters, BMI, waist circumference, blood pressure, physical activity, alcohol and tobacco consumption, and the homeostasis model assessment [HOMA-IR=(serum insulin $(\mu \mathrm{U} / \mathrm{mL}) \times$ blood glucose $(\mathrm{mmol} / \mathrm{L})) / 22.5]$.

\section{Safety of the dietary intervention}

At the quarterly interviews, the trial doctors questioned the participants to self-report their medical conditions and the appearance of acute affections that required medical assistance. Furthermore, at December 2018, a family physician collaborating with the trial, blinded to the assignment and not belonging to the trial staff, conducted a retrospective study of the electronic medical records of the participants. The period from recruitment up to two years after the completion of the trial was inspected, and all recorded analytical values of serum creatinine (marker of renal function) and alanine and aspartate aminotransferase (markers of hepatic disorder) were collected. In addition, the electronic medical records were also 
1 examined to gather all reported vascular events (cerebral, cardiac and peripheral) or other

2 adverse findings (including pathologies as cancer or neurodegenerative diseases).

3

\section{Ethics}

5 The Ethics and Health Research Committee of the Primary Health Care District Seville 6 (Andalusian Health Service, Andalusia, Spain) approved the protocol on May 20, 2008. All 7 participants signed their consent, after being informed of the objectives and methodology of 8 the trial. PREDIABOLE was conducted according to the recommendations of the Helsinki 9 Declaration and the Good Clinical Practice Guidelines of the International Council for Harmonization (www.ich.org).

\section{Statistical analysis}

The calculated sample size was 80 participants per group, assuming a two-tailed alpha of 0.05 , a statistical power greater than $80 \%$, and expected proportions of new cases of diabetes after 30 months' follow-up of $20 \%$ in the CG and of $5 \%$ in the IG. A dropout rate of up to $20 \%$ was considered.

The trial was conducted according to the intention-to-treat (ITT) principle. Qualitative variables were expressed by their absolute and relative frequencies, whereas the quantitative ones with normal distribution did so by the mean and standard deviation and those with non-normal distribution by the median and interquartile range (IQR). Comparisons between study groups for qualitative variables were done with the Chi-square and McNemar's tests, whereas comparisons for quantitative variables were executed with the Student's $t$ test and ANOVA. The homogeneity of the populations included in the allocation groups was evaluated using the Mann-Whitney-Wilcoxon U test.

Cox regression models were fitted to assess the relative risk of diabetes by allocation groups, estimating hazard ratios and $95 \% \mathrm{Cl}$. The 'time' variable was the interval between recruitment and the date of last follow-up or diabetes diagnosis, whichever occurred first. Participants who 
1 were free of diabetes or lost during follow-up were censored at the date of the last visit.

2 Interactions of the intervention with other variables were evaluated using the likelihood ratio

3 test for multiplicative product terms introduced in fully adjusted Cox models. The survival

4 analysis (probability of remaining free of diabetes during follow-up) was carried out comparing

5 the Kaplan-Meier curves by the log-rank method. All $p$ values were two-tailed at $\alpha=0.05$.

6 Statistical analysis was performed with the SPSS 24 (IBM SPSS Statistics, New York, USA)

7 software.

8

\section{$9 \quad$ Data accessibility statement}

The datasets generated during the trial are available from the corresponding author upon reasonable request. No applicable resources were generated or analysed during the PREDIABOLE Study.

\section{RESULTS}

\section{Eligibility/recruitment and baseline characteristics of participants}

From March 2010 to September 2015, 1728 individuals diagnosed of IFG were pointed as potential participants in the study. Of these, 947 did not meet inclusion criteria and 39 declined to participate. We performed 742 OGTT, identifying 176 individuals who fulfilled the requirements to be included in the trial. They were randomly allocated to the study groups, 92 to the $C G$ and 84 to the IG (Fig. 1). Both groups resulted well balanced with respect to all the variables considered (Table 1), including clinical characteristics. A Mann-Whitney-Wilcoxon Utest supported that both populations were identical at baseline for every considered item.

\section{Follow-up, compliance and dropouts}

Participants were followed for a median of 27.5 months (IQR 13.3-30.0) with no significant differences between the study groups [CG 25.0 (12.0-30.0); IG 30.0 (15.0-30.0)] (Table 2). 
1 Adherence to the trial was high and similar in both groups, as judged by the Haynes-Sackett

2 test and the return of the empty bottles consumed. The measurement of fasting plasma OA also might suggest good compliance (supplementary appendix), drawing a trend of increase with the follow-up time, although this was not translated in significant differences.

Twenty-seven dropouts were recorded during the trial, 12 in the CG (13.0\%) and 15 in the IG (17.9\%) (Figure 1). Since characteristics of individuals who dropped the study were no statistically different of those who completed it, the analysis of results was not biased by this unbalance.

Changes in body weight, waist circumference, blood pressure and blood lipids were minor and did not differ among the allocation groups. In addition, on-trial changes in medications that may influence the progression to diabetes, such as statins, hypertensive and lipid lowering drugs, were similarly distributed among the groups.

\section{End-points}

Forty-eight participants developed diabetes along the trial, 31 in the $C G$ and 17 in the IG (Table 2). The likelihood ratio test for the overall effect of the intervention indicates that there is a statistically significant association (Chi-square $4.069, p$ value 0.044 ) between the new onset diabetes cases and the olive oil consumed, which identifies the OA-enriched oil as a protective factor compared with the control oil. In fact, the consumption of the functional olive oil at the indicated daily dose (equivalent to $30 \mathrm{mg} \mathrm{OA}$ /day) would halve the risk of developing diabetes in prediabetic individuals [unadjusted HR 0.533 (0.289-0.981)].

Multivariable analysis confirmed the beneficial effect of the OA-based intervention. The hazard ratio after adjustment for potential confounders variables (sedentary lifestyle, insulin resistance and hypercholesterolemia), was 0.448 ( $\mathrm{Cl} 0.242$ to 0.825 ) ( $\mathrm{p}$ value 0.011 ), indicating a $55.2 \%$ relative risk reduction of incident diabetes by consuming the OA-enriched olive oil as compared with intaking the control oil. In mono- and multivariable Cox's regression models, 
sex, age, BMI, LDL-c, HDL-c, tobacco and alcohol addictions, were unrelated with the newonset diabetes cases.

The survival analysis (Kaplan-Meier) displayed patently the protective action of OA. The curve of cumulative diabetes incidence for the IG progressed always below that for the CG, diverging very clearly since the onset of the trial. The free diabetes survival time (mean \pm SD and 95\% Cl) was estimated in $27.0 \pm 0.8(25.5-28.5)$ months for the IG and $24.3 \pm 1.0(22.3-26.2)$ months for the CG. These values were determined statistically different by the log rank test of equality of survival distributions (Chi-square 4.315; $p$ value 0.038 ) (Figure 2).

\section{Safety of the dietary intervention}

Gastrointestinal symptoms or any other disarray were not revealed by the participants along the trial. On the other hand, the retrospective study of the participants' electronic medical records did not suggest that the oral administration of $30 \mathrm{mg} \mathrm{OA} /$ day increases incidence of cardiovascular events, stroke, cancer, neurodegenerative diseases, or kidney and liver disorders, when compared with the intake of commercial olive oil by individuals of the control group. Adverse clinical findings were detected in ten individuals (seven in the CG and three in the IG) (Table 3). Two of them (one in CG and the other in IG) displayed antecedents of vascular disease before recruitment. In consequence, it could be held that the use of the OAenriched olive oil at the recommended dose seems safe.

\section{DISCUSSION}

Evidence on the pharmacological potential of $O A$ in experimental models indicates that, if fully exploited, it offers interesting alternatives for diabetes management. Surprisingly, OA-based human trials and therapies have been scarce until now. The PREDIABOLE study provides data suggesting that a long-term OA-based intervention reduces diabetes incidence in people at high risk (IFG+IGT). After a median 27.5 months of follow-up, individuals intaking the OAenriched olive oil showed a significant $55.2 \%$ relative risk reduction when compared to those 
1 consuming the control oil (Table 2). This effect should be attributable primarily to the presence

2 of therapeutic concentrations of $O A$, since no other item was implemented differentially in the study groups. Recommendations on the overall diet composition, increased physical activity, weight loss, moderate consumption of alcohol or avoiding of tobacco, were given identically to both groups. This strong protective action against diabetes in humans is consistent with experimental evidence in animals showing improvements in glucose homeostasis, lipid metabolism and insulin signalling, as well as the reinforcement of the adaptive cell response to oxidative stress and inflammation, all recognized as pharmacological mechanisms of $\mathrm{OA} .^{12-}$ $14,32-34$

PREDIABOLE also suggests that the long term administration of a daily dose of $30 \mathrm{mg} O \mathrm{~A}$ is safe for prediabetic individuals, since no adverse effects related to the intervention were neither reported during the follow-up nor during the two subsequent years. OA has been considered as a very safe over-the-counter drug used for hepatoprotection and treating hepatitis in China for decades. ${ }^{35,36}$ A trial performed with 70 individuals suffering acute hepatitis informed no apparent side effects following the administration of $60-90 \mathrm{mg} \mathrm{OA} / \mathrm{day}$ for 30 days (Xu and Wan, 1980; in ${ }^{10}$ ). A similar trial with 188 patients of chronic hepatitis reported that this same OA treatment was postulated as safe when used for six months $(\mathrm{Xu}, 1985$; in $\left.{ }^{10}\right)$. Xi et al. (2009; in ${ }^{10}$ ) even reported that oral doses of up to 200-240 mg OA/day, alone or in combined therapies, did not cause apparent adverse effects (Xi et al., 2009; in ${ }^{35}$ ). In the same way, four trials performed in USA with patients (34-45 individuals) of osteoarthritis, rheumatoid arthrosis and fibromyalgia, using a phytochemical formulation which provides 40 $\mathrm{mg} \mathrm{OA}$ /tablet, not stated harmful effects on the markers of cardiovascular and gastrointestinal toxicity generally affected by the nonsteroidal anti-inflammatory drugs, after eight weeks of treatment. ${ }^{37}$ All these data together support the safety of the OA-based intervention in PREDIABOLE.

The PREDIABOLE study has limitations. First, since it involves a dietary intervention in autonomous adults with normal social lives, we cannot guarantee that they strictly followed the 
1 requiring consumption of olive oil nor the given recommendations. However, the Haynes-

2 Sackett test, the return of empty oil bottles, and even the plasma OA levels, suggest high adherence in both allocation groups. In recruiting of participants, we used interview models that had proved successful identifying people with good predisposition to change lifestyle and being compliant with the protocols. Likely, the formulation used for administering $O A$, an olive oil, explain the high acceptability of the intervention by the participants, since it is a highly valued food in Mediterranean societies and a key element in their dietary pattern. This fatty formulation might be thought inadequate for overweight/obese prediabetic people by hypercaloric. Rather, the PREDIMED trial showed that a long-term intervention with an adlibitum Mediterranean diet reinforced in extra virgin olive oil, without promotion of physical activity, caused no significant difference in body weight and even lower central adiposity in overweight/obese elder people at risk of cardiovascular disease, when compared with those consuming a low-fat control diet. ${ }^{38}$ Furthermore, OA lacks adipogenic activity, whereas some common antidiabetic agents often lead to weight gain. ${ }^{39}$

Second, the target population were people at high risk of diabetes (IFG + IGT), what could limit the generalization of the results to younger people or those less exposed to the disease development. Third, during the trial, slightly higher losses were recorded in the IG than in the CG. However, the high homogeneity in the anthropometric and clinical characteristics of both those who dropout and those who complete the study, minimized the bias in the analysis of the results.

Our study also has strengths. PREDIABOLE is a randomised trial designed and executed entirely in primary care, the gateway to the National Health System in Spain. This aspect supports the external validity and applicability of the results, and gives greater consistency to the evidence obtained, as it reproduces usual conditions of clinical practice. The randomization process for participants' allocation yielded study groups very well balanced avoiding potential sources of confounding and standing out the causal association between OA administration and diabetes prevention. The PREDIABOLE trial observed the ITT principle, 
1 what kept randomization until the end of the trial and decreased the probability of biasing.

2 Other strength of the trial was its double-blind design, in which both participants and health staff were unaware of the oils assigned to the study groups. This aspect is a clear advantage over studies in which the blinding of the dietary intervention was not feasible.

Testing the effect of the OA-enriched olive oil not against a placebo or a low-fat diet, but against the same olive oil unreinforced in the triterpene should be also considered a strength of the trial. Meta-analysis of the effects of olive oil-supplemented diets indicate that the consumption of olive oil is associated both with a decreased risk to develop the disease in healthy individuals and with an improvement of glucose homeostasis in diabetic patients. ${ }^{40}$ Most of those studies used virgin olive oil and focused their attention on the fatty acid composition or the presence of phenolics, overlooking the biological activity of other natural functional components of olive oils, such as OA. Therefore, the protective effect offered by the functional olive oil when compared with the control olive oil in the PREDIABOLE trial further stands out the antidiabetic action of OA and its therapeutic usefulness for humans.

In conclusion, the PREDIABOLE Study is a fully randomised, controlled, double-blind trial, well designed and executed, supporting that consumption of an OA-enriched olive oil results in a substantial risk reduction of developing type 2 diabetes in prediabetic patients. This dietary intervention is well accepted by the participants and also safe and palatable, showing high potential to be long-term sustainable.

The burst of diabetes prevalence in the last decades, demands urgent measures delaying or avoiding the appearance of the disease. In this scenario, the use of OA-enriched functional foods is an interesting strategy. Nevertheless, further research is needed to consolidate the evidence of PREDIABOLE and to extend the use of OA in the design of new foods and drugs.

Acknowledgments. The authors especially thank ACESUR Group (Dos Hermanas, Seville, Spain), which donated all the commercial olive oil for the trial. This collaborator had no role in the design, collection, analysis, or interpretation of the data or in the decision to submit the 
manuscript for publication. The authors also express their gratitude to Dr. Alberto Gil-Peralta, Neurology Service of the Virgen del Rocío University Hospital (Seville, Spain), for the critical reading of the manuscript and his helpful comments. CIBEROBN is an initiative of Instituto de Salud Carlos III (ISCIII), Madrid, Spain.

Funding. The PREDIABOLE trial was supported by de official funding agency for biomedical research of the Spanish government, ISCIII, through the Fondo de Investigación para la Salud (FIS), which is co-funded by the European Regional Development Fund, including the following projects: PI10/00913 (led by J.M.S-L.) and PI10/01415 (led by J.A.C.). The study was also supported by grant of Consejería de Salud de la Junta de Andalucía (PI-0037/2008, led by J.M.S-L.).

None of the funding sources took part in the design, collection, analysis, or interpretation of the data or in the decision to submit the manuscript for publication.

Duality of Interest. No potential conflicts of interest relevant to this article were reported.

Author Contributions. JM Santos-Lozano, J Lapetra. and JM Castellano contributed to the study design. M Rada, Á Guinda, JA Cayuela, MC Jiménez-Rodríguez, A Ángel-Lugo, AM Gómez-Martín, J Lapetra and JM Castellano contributed to data acquisition. M Rada., M Ortega-Calvo, Á Vilches-Arenas, J Lapetra, JM Santos-Lozano and JM Castellano contributed to data analysis. JM Castellano wrote the manuscript.

JM Santos-Lozano and JM Castellano are the guarantors of this work and, as such, had full access to all the data in the study and takes responsibility for the integrity of the data and the accuracy of the data analysis. They were responsible for the integrity of the work as a whole.

\section{REFERENCES}

1. Cho NH, Shaw JE, Karuranga S, Huang Y, da Rocha Fernandes JD, Ohlrogge AW, Malanda B. IDF Diabetes Atlas: Global estimates of diabetes prevalence for 2017 and 
projections for 2045. Diabetes Res Clin Pract 2018;138:271-281. https://doi.org/10.1016/j.diabres.2018.02.023

2. Pour OR, Dagodo JS. Prediabetes as a therapeutic target. Clin Chem 2011;57:215220. https://doi: 10.1373/clinchem.2010.149096

3. American Diabetes Association. Classification and Diagnosis of Diabetes: Standards of Medical Care in Diabetes-2019. Diabetes Care 2019;42(Suppl. 1):S13-S28. https://doi.org/10.2337/dc19-S002

4. Bansal N. Prediabetes diagnosis and treatment: A review. World J Diabetes 2015;15: 296-303. https://doi: 10.4239/wjd.v6.i2.296

5. Valdés S, Botas $\mathrm{P}$, Delgado $\mathrm{E}$, Álvarez F, Díaz-Cadórniga F. Population-based incidence of type 2 diabetes in Northern Spain. Diabetes Care 2007;30:2258-2263. https:// doi.org/10.2337/dc06-2461

6. Jäger S, Trojan H, Kopp T, Laszczyk MN, Scheffler A. Pentacyclic triterpene distribution in various plants - rich sources for a new group of multi-potent plant extracts. Molecules 2009;14:2016-2031. https:// doi.org/10.3390/molecules14062016

7. Guinda A, Rada M, Delgado T, Gutiérrez-Adánez $P$, Castellano JM. Pentacyclic triterpenoids from olive fruit and leaf. J Agric Food Chem 2010;58:9685-9691. https://doi:10.1021/jf102039t

8. Pérez-Camino MC, Cert A. Quantitative Determination of Hydroxy Pentacyclic Triterpene Acids in Vegetable Oils. J Agric Food Chem 1999;47:1558-1562. https://doi: $10.1021 /$ jf980881h

9. Liu J. Pharmacology of oleanolic acid and ursolic acid. J Ethnopharmacol 1995;49:5768. https:// doi.org/10.1016/0378-8741(95)90032-2

10. Liu J. Oleanolic acid and ursolic acid: research perspectives. J Ethnopharmacol 2005;100:92-94. https://doi.org/10.1016/j.jep.2005.05.024

11. Dzubak P, Hajduch M, Vydra D, et al. Pharmacological activities of natural triterpenoids and their therapeutic implications. Nat Prod Rep 2006;23:394-411. https://doi.org/10.1039/b515312n

12. Ayeleso TB, Matumba MG, Mukwevho E. Oleanolic Acid and Its Derivatives: Biological Activities and Therapeutic Potential in Chronic Diseases. Molecules 2017;22:1915, https://doi.org/10.3390/molecules22111915

13. Wang Z, Hsu C, Huang C, Yin M. Anti-glycative effects of oleanolic acid and ursolic acid in kidney of diabetic mice. Eur $J$ Pharmacol 2010;628(1-3):255-260. https://doi.org/10.1016/j.ejphar.2009.11.019

14. Castellano JM, Guinda Á, Delgado T, Rada M, Cayuela JA. Biochemical Basis of the Antidiabetic Activity of Oleanolic Acid and Related Pentacyclic Triterpenes. Diabetes 2013;62:1791-1799. https://doi.org/10.2337/db12-1215

15. Clinical trial ISRCTN22685192 (2009) "A double-blind, randomised controlled trial to assess the bioavilability of triterpenoids from pomace oil and their role on processes involved in the formation of the atheroclerotic plaque". Available from http://isrctn.com/ISRCTN22685192

16. Clinical trial NCT01674946 (2011) "Effect of Intraduodenal Perfusion of Bile Acids on the Secretion of Gastrointestinal Satiation Peptides in Healthy Male Volunteers". Available from http://clinicaltrials.gov/show/NCT01674946

17. Luo H, Shen J, Chen C-P, et al. Lipid-lowering effects of oleanolic acid in hyperlipidemic patients. Chin J Nat Med 2018;16:339-346. https:// doi.org/10.1016/S1875-5364(13)60016-3

18. Liu Y, Luo X, Xu X, Gao N, Liu X. Preparation, characterization and in vivo pharmacokinetic study of PVP-modified oleanolic acid liposomes. Int $\mathrm{J}$ Pharm 2017;517:1-7. https://doi.org/10.1016/j.ijpharm.2016.11.056

19. Zhang W, Liang C, Liu H, et al. Polymeric nanoparticles developed by vitamin Emodified aliphatic polycarbonate polymer to promote oral absorption of oleanolic acid. Asian J Pharm Sci 2017;12:586-593. https://doi.org/10.1016/j.ajps.2017.08.003 
20. Chu F, Zhang W, Guo W, et al. Oleanolic Acid-amino Acids Derivatives: Design, Synthesis, and Hepatoprotective Evaluation In Vitro and In Vivo. Molecules 2018;23:322. https://doi.org/10.3390/molecules23020322

21. Rada M, Castellano JM, Perona JS, Guinda Á. GC-FID determination and pharmacokinetic studies of oleanolic acid in human serum. Biomed Chromatogr 2015;29:1687-1692. https://doi.org/10.1002/bmc.3480

22. Song M, Hang TJ, Wang $Y$, et al. Determination of oleanolic acid in human plasma and study of its pharmacokinetics in Chinese healthy male volunteers by HPLC tandem mass spectrometry. J Pharm Biomed Anal 2006;40: 190-196. https://doi.org/10.1016/j.jpba.2005.06.034

23. Chen RJ, Liu X, Li PM, Zhang L, Zhao L and Zhang XL. Pharmacokinetic profiles of oleanolic acid formulations in healthy Chinese male volunteers. Chinese Pharm $\mathrm{J}$ 2010;45:621-626.

24. American Diabetes Association. Diagnosis and Classification of Diabetes Mellitus. Diabetes Care 2008;31:Supplement 1, S55-S60. https://doi.org/10.2337/dc08-S055

25. World Health Organization and International Diabetes Federation (1999). Definition, diagnosis and classification of diabetes mellitus and its complications. Geneva, Switzerland. Available from https://apps.who.int/iris/handle/10665/66040

26. Spanish Patent ES2160553 (2001). Procedure for the obtaining of terpenic acids from the leaf of Olea europaea. Guinda Á, Alti T, Lanzón A.

27. European Patent EP18382510 (2018). Olive oil enriched with oleanolic acid, process for its preparation and use thereof. Castellano JM, Rada M, Guinda Á, Santos-Lozano JM, Lapetra J.

28. International Olive Oil Council (2016). Document COI/T.15/NC no 3/Rev. 11. Available from http://www.internationaloliveoil.org/documents/viewfile/9708-norma-english

29. Commission Regulation (EEC) (1991) No 2568/91 on the characteristics of olive oil and olive-residue oil and on the relevant methods of analysis. Available from https://eurlex.europa.eu/legal-content/EN/TXT/?uri=CELEX\%3A01991R2568-20151016

30. International Olive Oil Council (2007). Document COI/T.20/Doc.15/Rev. 2. Available from http://www.internationaloliveoil.org/documents/viewfile/3685-orga6

31. Rodríguez-Chamorro MA, García-Jiménez E, Amariles $P$, Rodríguez-Chamorro $A$, Faus MJ. Review of therapeutic compliance measurement tests used in clinical practice [Revisión de test de medición del cumplimiento terapéutico utilizados en la práctica clínica]. Aten Primaria 2008;40:413-417. https://doi.org/10.1157/13125407

32. Li M, Han Z, Bei W, Rong X, Guo J, Hu X. Oleanolic Acid Attenuates Insulin Resistance via NF-KB to regulate the IRS1-GLUT4 Pathway in HepG2 Cells. Evid. Based Complement Altern Med, vol 2015, Article ID 643102, 9 pages. https://doi.org/10.1155/2015/643102

33. Mukundwa A, Mukaratirwa S, Masola B. Effects of oleanolic acid on the insulin signaling pathway in skeletal muscle of streptozotocin-induced diabetic male SpragueDawley rats. J. Diabetes 2016;8:98-108. https://doi.org/10.1111/1753-0407.1226

34. Castellano JM, Guinda A, Macías L, Santos-Lozano JM, Lapetra J, Rada M. Free radical scavenging and $\alpha$-glucosidase inhibition, two potential mechanisms involved in the anti-diabetic activity of oleanolic acid. Grasas y Aceites 2016;67:e142. http://dx.doi.org/10.3989/gya.1237153

35. Pollier J, Goossens A. Oleanolic acid. Phytochemistry 2012;77:10-15. https://doi.org/10.1016/j.phytochem.2011.12.022

36. Lin C, Wen X, Sun H. 2016. Oleanolic acid derivatives for pharmaceutical use: a patent review. Expert Opinion on Therapeutic Patents 26(6):643-655. https://doi.org/10.1080/13543776.2016.1182988

37. Minich DM, Bland JS, Katke J, Darland G, Hall A, Lerman RH, Lamb J, Carroll B, Tripp M. (2007) Cinical safety and efficacy of NG440: a novel combination of rho iso-alpha acids from hopps, rosemary, and oleanolic acid for inflammatory conditions. Canadian Journal of Physiology and Pharmacology 85:872-883. https://doi.org/10.1139/Y07-055 
38. Estruch R, Martínez-González MA, Corella D, et al. Effect of a high-fat Mediterranean diet on bodyweight and waist circumference: a prespecified secondary outcomes analysis of the PREDIMED randomised controlled trial. Lancet Diabetes Endocrinol 2019;7(5):e6-e17. https://doi.org/10.1016/S2213-8587(19)30074-9

39. Sung HY, Kang SW, Kim JL, et al. Oleanolic acid reduces markers of differentiation in 3T3-L1 adipocytes. Nutr Res 2010;30:831-839. https://doi.org/ 10.1016/j.nutres.2010.10.001

40. Schwingshackl L, Lampousi A-M, Portillo MP, Romaguera D, Hoffmann G, Boeing H. Olive oil in the prevention and management of type 2 diabetes mellitus: a systematic review and meta-analysis of cohort studies and intervention trials. Nutr Diabetes 2017;7:e262. https://doi.org/10.1038/nutd.2017.12 
Table 1. Baseline characteristics of prediabetic participants according to study groups

\begin{tabular}{|c|c|c|}
\hline & control oil & OA-enriched oil \\
\hline $\mathrm{n}$ & 92 & 84 \\
\hline age (years) & $67.4 \pm 9.2$ & $67.9 \pm 9.0$ \\
\hline male sex (\%) & 53.2 & 48.8 \\
\hline weight (kg) & $81.7 \pm 14.9$ & $81.4 \pm 15.1$ \\
\hline height $(\mathrm{cm})$ & $162.7 \pm 9.7$ & $163.8 \pm 10.2$ \\
\hline BMI $\left(\mathrm{kg} / \mathrm{cm}^{2}\right)$ & $30.7 \pm 4.2$ & $30.1 \pm 4.1$ \\
\hline waist circumference (cm) & $110.5 \pm 10.2$ & $108.1 \pm 9.1$ \\
\hline $\mathrm{SBP}(\mathrm{mm} \mathrm{Hg}) \dagger$ & $127.9 \pm 15.7$ & $130.2 \pm 16.6$ \\
\hline $\mathrm{DBP}(\mathrm{mm} \mathrm{Hg})$ & $74.8 \pm 9.3$ & $75.8 \pm 10.0$ \\
\hline \multicolumn{3}{|l|}{ plasma biomarkers } \\
\hline fasting glucose (mg/dL) & $112.5 \pm 17.7$ & $106.2 \pm 14.6$ \\
\hline $\mathrm{HbA} 1 \mathrm{c}[\%(\mathrm{mmol} / \mathrm{mol}$ IFCC)] & $6.0 \pm 0.4(42.0 \pm 4.4)$ & $5.8 \pm 0.5(40.0 \pm 5.5)$ \\
\hline fasting insulin ( $\mu \mathrm{U} / \mathrm{mL})$ & $15.4 \pm 6.4$ & $16.2 \pm 5.2$ \\
\hline HOMA-IR $\ddagger$ & $4.3 \pm 2.2$ & $3.9 \pm 2.3$ \\
\hline triglycerides (mg/dL) & $144.5 \pm 63.1$ & $141.3 \pm 67.4$ \\
\hline total cholesterol (mg/dL) & $204.0 \pm 40.0$ & $203.8 \pm 36.1$ \\
\hline $\mathrm{LDL}(\mathrm{mg} / \mathrm{dL})$ & $121.9 \pm 33.8$ & $121.9 \pm 31.6$ \\
\hline $\mathrm{HDL}(\mathrm{mg} / \mathrm{dL})$ & $54.7 \pm 14.2$ & $55.4 \pm 17.5$ \\
\hline hs-CRP(mg/L) § & $2.4 \pm 2.0$ & $2.4 \pm 2.5$ \\
\hline \multicolumn{3}{|l|}{ medication use [n (\%)] } \\
\hline ACE inhibitors / ARB ף & $42(45.2 \%)$ & $39(46.4 \%)$ \\
\hline diuretics & $22(23.9 \%)$ & $18(21.4 \%)$ \\
\hline other antihipertensive agents & $26(28.3 \%)$ & $20(23.8 \%)$ \\
\hline statins & $34(37.0 \%)$ & $30(35.7 \%)$ \\
\hline others lipid lowering agents & $3(3.3 \%)$ & $4(4.8 \%)$ \\
\hline \multicolumn{3}{|l|}{ living habits } \\
\hline tobacco (cigarettes/day) & $20.1 \pm 12.4$ & $21.2 \pm 16.3$ \\
\hline alcohol (units/week) & $9.6 \pm 11.9$ & $10.2 \pm 14.2$ \\
\hline sedentary lifestyle (\%) & 51.5 & 59.5 \\
\hline family antecedent of diabetes (\%) & 57.6 & 48.8 \\
\hline prediabetes evolution (months) & $22.3 \pm 17.9$ & $19.8 \pm 18.2$ \\
\hline
\end{tabular}

Results are expressed as mean \pm SD or percentages

All variables passed the Mann-Whitney-Wilcoxon U-test to assess the population homogeneity † SBP and DBP means systolic and diastolic blood pressures, respectively.

$\ddagger$ HOMA-IR $=($ serum insulin $(\mu \mathrm{U} / \mathrm{mL}) \times$ blood glucose $(\mathrm{mmol} / \mathrm{L})) / 22.5$

$\S$ hs-CRP denotes high-sensitivity C-Reactive Protein

I ACE (angiotensin-converting enzyme) inhibitors /ARB (angiotensin receptor blocker) 
Table 2. Incidence of diabetes after a median follow-up of 27.5 months and relative risk of diabetes by

OA-enriched oil control oil $p$ value participants

allocation groups 
months follow-up [median (IQR)]

person-months of follow-up

events

new onset diabetes

incidence rate per 1000 persons-months (95\%

Cl)

hazard ratio $(95 \% \mathrm{Cl}) \dagger$

a) univariable analysis

olive oil type (crude model)

sex

age

BMI

waist circumference

fasting glucose

$\mathrm{HbA1c}$

fasting insulin

HOMA-IR

TG

TC

LDL

HDL

hypertension $\ddagger$

sedentary lifestyle

alcohol

tobacco

b) multivariable analysis

multivariable adjusted model-1§

multivariable adjusted model-2ๆ
$25.0(12.0-30.0)$

1923

17

$8.8(5.1-14.2)$

$16.3(11.1-23.1)$

$\begin{array}{lcc}0.542(0.300-0.980) & 1 \text { (ref.) } & 0.043 \\ 1.066(0.605-1.878) & \text { “ } & 0.825 \\ 0.991(0.960-1.023) & & 0.595 \\ 1.489(0.845-2.657) & & 0.166 \\ 1.004(0.985-1.045) & & 0.345 \\ 1.066(1.048-1.085) & & <0.001 \\ 3.914(2.068-7.406) & & <0.001 \\ 1.054(1.018-1.091) & & 0.003 \\ 2.724(1.501-4.945) & & 0.001 \\ 1.004(0.999-1.008) & & 0.103 \\ 1.994(1.094-3.637) & & 0.024 \\ 1.008(0.999-1.017) & & 0.081 \\ 1.007(0.989-1.025) & & 0.441 \\ 1.229(0.706-2.140) & & 0.465 \\ 0.901(0.510-1.589) & & 0.718 \\ 1.010(0.994-1.026) & & 0.224 \\ 1.802(0.871-3.726) & & 0.112 \\ 0.489(0.269-0.891) & 1 \text { (ref.) } & 0.019 \\ 0.448(0.242-0.825) & 1 \text { (ref.) } & 0.011\end{array}$

†Cox's regression models were used to assess the relative risk of diabetes for allocation group, estimating HR and $95 \% \mathrm{Cl}$.

‡ Individuals were considered as hypertensive if $\mathrm{DBP}>90 \mathrm{mmHg}$ or $\mathrm{SBP}>140 \mathrm{mmHg}$.

$\S$ Multivariable model adjusted for insulin resistance (HOMA-IR $\geq 3.8$ yes; else no) and hypercholesterolemia ( $T C \geq 200 \mathrm{mg} / \mathrm{dL}$ yes; else no).

TAdditionally adjusted for sedentary lifestyle (physical activity null/scarce $=0 ;$ moderate/intense $=1$ ) 
Table 3. Individuals with significant health events, appearing during their participation in the trial (during) and/or the two-years period after their completion (post).

\begin{tabular}{|c|c|c|c|c|c|c|}
\hline case $n^{\circ}$ & oil type & event & period & $\begin{array}{l}\text { other } \\
\text { finding }\end{array}$ & antecedents & death \\
\hline 1 & control & $\begin{array}{c}\text { elevated } \\
\text { ALT+AST } †\end{array}$ & post & $\begin{array}{l}\text { Cancer } \\
\text { (lung) }\end{array}$ & - & + \\
\hline 2 & control & $\begin{array}{l}\text { transient } \\
\text { ischemic } \\
\text { stroke }\end{array}$ & post & - & - & - \\
\hline 3 & control & $\begin{array}{l}\text { ischemic } \\
\text { heart } \\
\text { disease }\end{array}$ & post & - & - & - \\
\hline 4 & control & $\begin{array}{c}\text { elevated } \\
\text { creatinine }\end{array}$ & post & $\begin{array}{l}\text { Cancer } \\
\text { (bladder) }\end{array}$ & $\begin{array}{l}\text { ischemic } \\
\text { heart } \\
\text { disease }\end{array}$ & - \\
\hline 5 & control & stroke & during & - & - & - \\
\hline 6 & control & $\begin{array}{l}\text { ischemic } \\
\text { heart } \\
\text { disease }\end{array}$ & $\begin{array}{l}\text { during } \\
\text { and post }\end{array}$ & angina & - & - \\
\hline 7 & control & $\begin{array}{l}\text { peripheral } \\
\text { arterial } \\
\text { disease }\end{array}$ & post & - & - & - \\
\hline \multirow[t]{2}{*}{8} & OA-enriched & $\begin{array}{l}\text { elevated } \\
\text { creatinine }\end{array}$ & during & $\begin{array}{l}\text { Cancer } \\
\text { (lung) }\end{array}$ & - & - \\
\hline & & $\begin{array}{l}\text { elevated } \\
\text { ALT+AST }\end{array}$ & post & - & - & - \\
\hline 9 & OA-enriched & $\begin{array}{l}\text { chronic } \\
\text { ischemia }\end{array}$ & post & - & $\begin{array}{l}\text { transient } \\
\text { ischemic } \\
\text { stroke }\end{array}$ & - \\
\hline 10 & OA-enriched & effort angina & during & - & - & \\
\hline
\end{tabular}




\section{FIGURE LEGENDS}

Fig.1. Flow diagram of the PREDIABOLE Study. †Denotes people with at least two IFG (fasting glucose $100-125 \mathrm{mg} / \mathrm{dL}$ ) values reported in the last six months. $\ddagger$ Standard $75 \mathrm{~g}$ oral glucose tolerance test.

Fig. 2. Kaplan-Meier estimation of cumulative incidence of diabetes by allocation groups. 
Figure 1

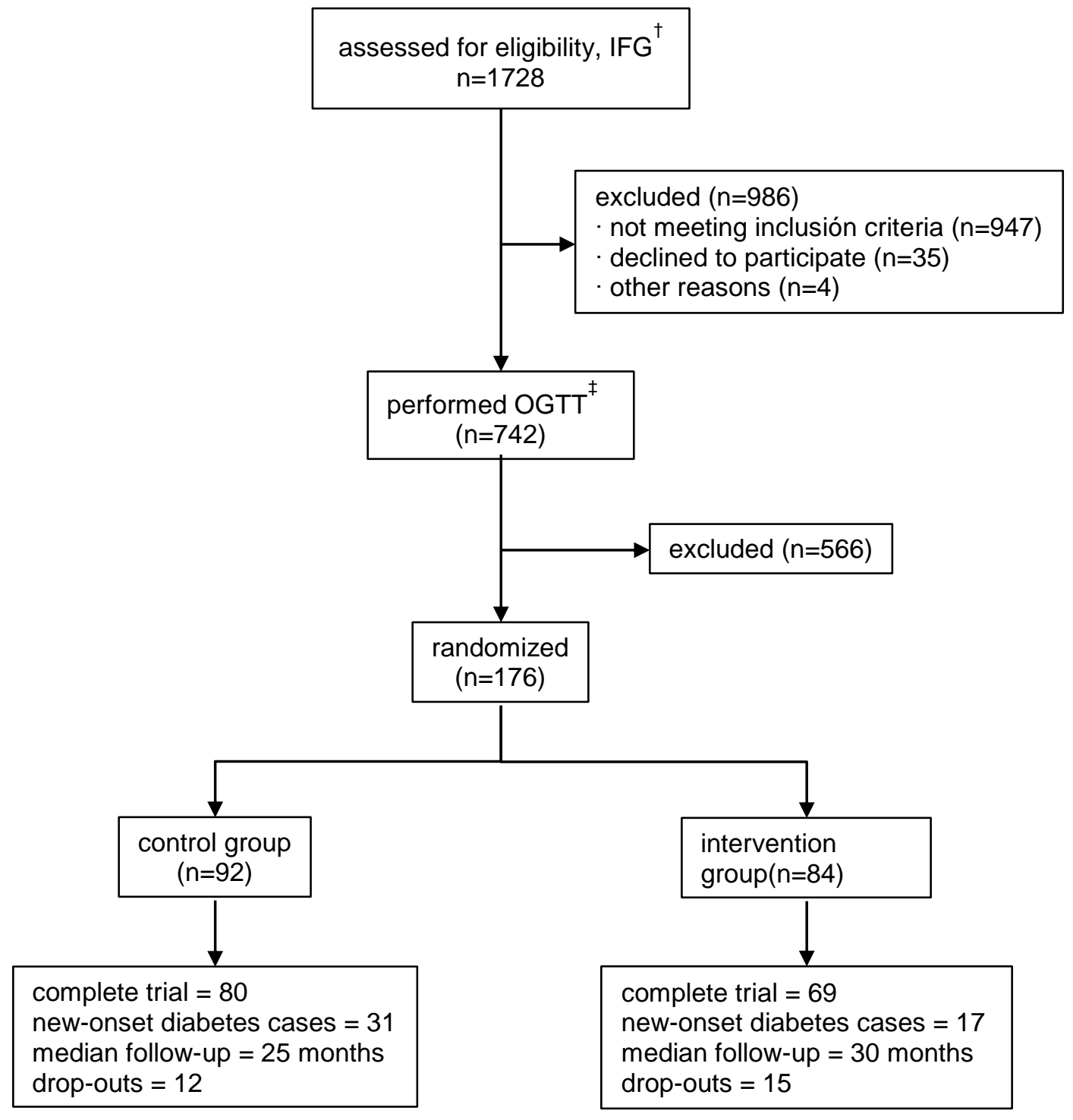


Figure 2

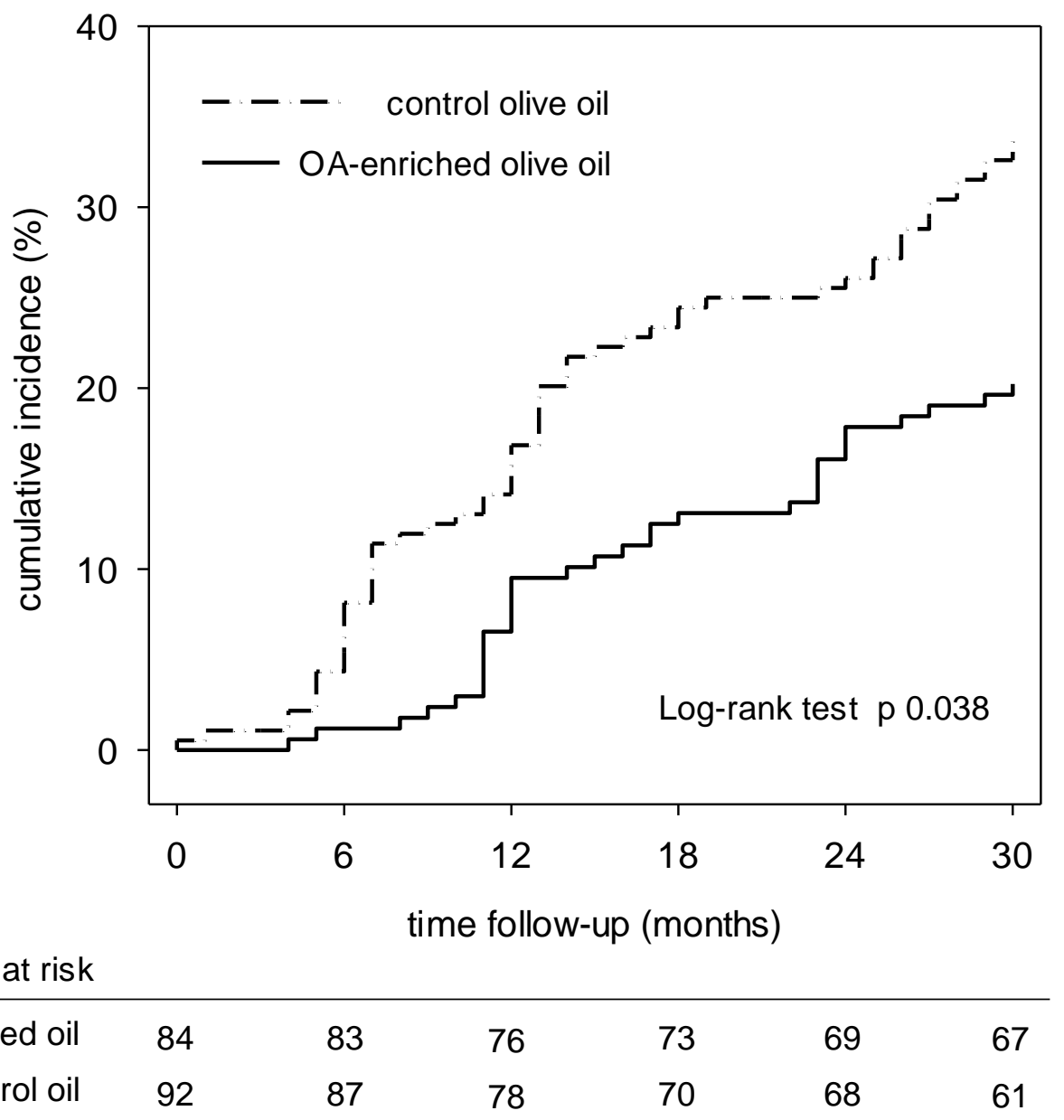

